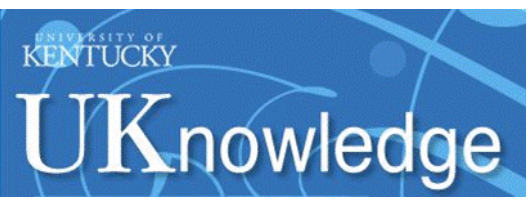

University of Kentucky

UKnowledge

$5-15-2017$

\title{
The Effects of Nicotine in the Neonatal Quinpirole Rodent Model of Psychosis: Neural Plasticity Mechanisms and Nicotinic Receptor Changes
}

Daniel J. Peterson

East Tennessee State University

W. Drew Gill

East Tennessee State University

John M. Dose

St. Norbert College

Donald B. Hoover

East Tennessee State University

See next page for additional authors

Right click to open a feedback form in a new tab to let us know how this document benefits you. Follow this and additional works at: https://uknowledge.uky.edu/ps_facpub

Part of the Experimental Analysis of Behavior Commons, Neuroscience and Neurobiology Commons, and the Pharmacy and Pharmaceutical Sciences Commons 


\section{The Effects of Nicotine in the Neonatal Quinpirole Rodent Model of Psychosis: Neural Plasticity Mechanisms and Nicotinic Receptor Changes}

Digital Object Identifier (DOI)

https://doi.org/10.1016/j.bbr.2017.02.029

Notes/Citation Information

Published in Behavioural Brain Research, v. 325, part A, p. 17-24.

(C) 2017 Published by Elsevier B.V.

This manuscript version is made available under the CC-BY-NC-ND 4.0 license

https://creativecommons.org/licenses/by-nc-nd/4.0/.

The document available for download is the author's post-peer-review final draft of the article.

\section{Authors}

Daniel J. Peterson, W. Drew Gill, John M. Dose, Donald B. Hoover, James R. Pauly, Elizabeth D. Cummins, Katherine C. Burgess, and Russell W. Brown 


\title{
The effects of nicotine in the neonatal quinpirole rodent model of psychosis: Neural plasticity mechanisms and nicotinic receptor changes
}

\author{
Daniel J. Peterson ${ }^{a}$, W. Drew Gill ${ }^{b}$, John M. Dose ${ }^{c}$, Donald B. Hoover ${ }^{b}$, James R. Pauly ${ }^{d}$, \\ Elizabeth D. Cummins ${ }^{a}$, Katherine C. Burgess ${ }^{b}$, and Russell W. Brown ${ }^{b,}{ }^{*}$ \\ aDepartment of Psychology, East Tennessee State University, Johnson City, TN 37614, United \\ States \\ bDepartment of Biomedical Sciences, James H. Quillen College of Medicine, East Tennessee \\ State University, Johnson City, TN 37614, United States \\ 'Department of Psychology, St. Norbert College, De Pere, WI, 54115, United States \\ dDepartment of Pharmaceutical Sciences, College of Pharmacy, University of Kentucky, \\ Lexington, KY 40536, United States
}

\section{Abstract}

\begin{abstract}
Neonatal quinpirole (NQ) treatment to rats increases dopamine D2 receptor sensitivity persistent throughout the animal's lifetime. In Experiment 1, we analyzed the role of $\alpha 7$ and $\alpha 4 \beta 2$ nicotinic receptors (nAChRs) in nicotine behavioral sensitization and on the brain-derived neurotrophic factor (BDNF) response to nicotine in NQ- and neonatally saline (NS)-treated rats. In Experiment 2 , we analyzed changes in $\alpha 7$ and $\alpha 4 \beta 2 \mathrm{nAChR}$ density in the nucleus accumbens (NAcc) and dorsal striatum in NQ and NS animals sensitized to nicotine. Male and female Sprague-Dawley rats were neonatally treated with quinpirole $(1 \mathrm{mg} / \mathrm{kg})$ or saline from postnatal days $(\mathrm{P}) 1-21$. Animals were given ip injections of either saline or nicotine $(0.5 \mathrm{mg} / \mathrm{kg}$ free base) every second day from P33 to P49 and tested on behavioral sensitization. Before each injection, animals were ip administered the a $7 \mathrm{nAChR}$ antagonist methyllycaconitine (MLA; 2 or $4 \mathrm{mg} / \mathrm{kg}$ ) or the a $4 \beta 2$ $\mathrm{nAChR}$ antagonist dihydro beta erythroidine (Dh $\beta \mathrm{E} ; 1$ or $3 \mathrm{mg} / \mathrm{kg}$ ).
\end{abstract}

Results revealed NQ enhanced nicotine sensitization that was blocked by DhßE. MLA blocked the enhanced nicotine sensitization in NQ animals, but did not block nicotine sensitization. NQ enhanced the NAcc BDNF response to nicotine which was blocked by both antagonists. In Experiment 2, NQ enhanced nicotine sensitization and enhanced $\alpha 4 \beta 2$, but not $7, \mathrm{nAChR}$ upregulation in the NAcc. These results suggest a relationship between accumbal BDNF and a $4 \beta 2$ nAChRs and their role in the behavioral response to nicotine in the NQ model which has relevance to schizophrenia, a behavioral disorder with high rates of tobacco smoking.

\footnotetext{
"Corresponding author: brown1@etsu.edu (R.W. Brown).
} 


\section{Keywords}

Dopamine D2 receptor; Nicotine sensitization; Brain-derived neurotrophic factor (BDNF); a 7 nicotinic receptor; a $4 \beta 2$ nicotinic receptor; Adolescence

\section{Introduction}

Individuals diagnosed with schizophrenia smoke tobacco at a much higher rate than the general population, and the prevalence rate of smoking among individuals diagnosed with schizophrenia is as much as $88 \%$ [1,2]. In addition, individuals diagnosed with schizophrenia smoke tobacco in a manner different than that of the general population, as their nicotine intake appears to be higher compared to the normal population. A study by Weinberger et al. [3] demonstrated that individuals diagnosed with schizophrenia have higher levels of plasma nicotine and plasma cotinine (a metabolite of nicotine) compared to control smokers, even when controlling for the amount smoked per day. Consistent with these findings, Williams et al. [4] showed that 3-hydroxycotinine, a metabolite of cotinine, was not altered among schizophrenia patients who smoke, suggesting that the increased plasma nicotine levels are due to increased nicotine intake rather than alterations in metabolism.

Kostrzewa et al. [5] were the first to report that animals treated neonatally with quinpirole, a dopamine $\mathrm{D}_{2} / \mathrm{D}_{3}$ receptor agonist, administered from postnatal days $(\mathrm{P}) 1-11,1-21$, or 2135 produces an increase in sensitivity of the $\mathrm{D}_{2}$ receptor, and this change is independent of a change in $\mathrm{D}_{2}$ receptor number. Increases of dopamine $\mathrm{D}_{2}$ sensitivity is a hallmark characteristic in schizophrenia, and these findings are consistent with past work that has suggested that although there are abnormalities in other neurotransmitter systems in schizophrenic patients, all of these abnormalities may be the result of dopamine $\mathrm{D}_{2}$ supersensitivity [6,7]. In a series of studies, we have shown that increases in dopamine $\mathrm{D}_{2}$ sensitivity produced by neonatal quinpirole has several consistencies with schizophrenia and, in fact, we have yet to find a data point that is inconsistent with the disorder [for a review,see 8]. While there are other neurotransmitter alterations that are present in schizophrenia that have yet to be investigated e.g., NMDA receptor hypofunction [for a review,see 9], findings from the neonatal quinpirole model have attained all three types of validity: face validity in cognitive impairment and PPI deficits [10,11]; construct validity in significant decreases of neurotrophic factors [12] and decreases of RGS9 expression [13], and predictive validity, with findings that olanzapine (atypical antipsychotic) treatment alleviated cognitive impairment and decreases of neurotrophic factor protein [10].

Behavioral sensitization is defined as an augmented motor response that occurs with repeated and/or intermittent exposure to a drug. Sensitization to drugs of abuse has been described as a progressive and prolonged increase in the locomotor activating effects, such as horizontal movement and stereotypy following repeated administration [14]. Based on the behavioral and cellular changes that are induced from psychostimulant exposure, sensitization is generally accepted as an effective model for the acquisition of addiction in humans [15]. Although many neural substrates appear to contribute to psychostimulant- 
induced sensitization, the mesolimbic dopamine system plays a critical role [16,17]. We have shown that neonatal quinpirole enhances nicotine behavioral sensitization in both adolescent [18] and adult male and female rats [19]. In addition, it enhances the response of brain-derived neurotrophic factor (BDNF) in the nucleus accumbens [20], a brain area known to play a critical role in both behavioral sensitization and the rewarding aspects of drugs, including nicotine [21]. BDNF is involved in synaptic differentiation and maintenance, and plays a critical role in addiction [22].

The present study was designed to analyze several different aspects of nicotine behavioral sensitization in male and female rats treated neonatally with quinpirole. In both experiments, we targeted adolescence because this is a critical developmental period when smoking behavior often begins, especially in cases of substance abuse comorbidity with behavioral disorders [23]. In Experiment 1, rats neonatally treated with quinpirole were sensitized to nicotine in adolescence, however, on each day of behavioral testing, we evaluated effects of either $2 \mathrm{mg} / \mathrm{kg}$ or $4 \mathrm{mg} / \mathrm{kg}$ of methyllycaconitine (MLA), an a 7 nicotinic receptor antagonist (nAChR) or $1 \mathrm{mg} / \mathrm{kg}$ or $3 \mathrm{mg} / \mathrm{kg}$ of di-hydro $\beta$-erythroidine (Dh $\beta \mathrm{E})$, an a $4 \beta 2 \mathrm{nAChR}$ antagonist. These nAChRs were chosen because they have been shown to be important in the behavioral effects of nicotine [24] in rodents, but there have not been any studies to analyze the roles of these two nAChRs in nicotine behavioral sensitization in adolescence. In addition, brain tissue was analyzed for BDNF. In a second experiment, animals were again neonatally treated with quinpirole, sensitized to nicotine, and brain tissue analyzed for a 7 and $a 4 \beta 2 \mathrm{nAChR}$ binding in the dorsal striatum and nucleus accumbens to characterize the changes in nAChRs relative to behavioral sensitization to nicotine in this model.

\section{Methods}

\section{Subjects}

A total of 177 offspring from 19 pregnant female Sprague-Dawley rats ordered from Harlan, Inc (Indianapolis, IN) were used as subjects. The day of birth was recorded as postnatal day (P)0. All animals were weaned from the female dam at P21, socially housed 3-4 per cage, and behaviorally tested as adolescents (P30-P49). Adolescence in the rat is based on both neurobiological changes as well as behaviors that have been associated with adolescence. More specifically, several studies have characterized adolescence based on neurobiological changes beginning on P30 and ultimately ending around P60 based on behavioral and neurobiological changes during this period [25]. One male and one female were used per litter per drug condition to control for within litter variance. The animals were housed in a climate-controlled vivarium with food and water available ad libitum with a $12 \mathrm{~h}$ on/off light/dark cycle. All procedures were approved by the University Committee on Animal Care (UCAC) at East Tennessee State University and the vivarium is fully accredited by the Association for the Assessment and Accreditation of Laboratory Animal Care (AAALAC). Animals were given a single daily intraperitoneal (ip) injection of either quinpirole (1 $\mathrm{mg} / \mathrm{kg}$ ) or saline from P1 to 21 . All animals were administered $1 \mathrm{mg} / \mathrm{kg}$ quinpirole based on body weight and were placed back into the home cage immediately after injections. 


\section{Behavioral Sensitization Apparatus}

All animals were tested in a locomotor testing arena painted flat black and measured $91 \mathrm{~cm}$ on each side. Horizontal activity was measured by ANY-Maze software (Stoelting, Wood Dale, IL), which superimposes a digital grid of lines on to the image of the locomotor arena. The dependent measure of behavioral sensitization was the total distance traveled in meters (m).

\section{Experiments 1 and 2. Behavioral Sensitization Procedure}

All animals were habituated to the locomotor testing area for three consecutive days from P30-32. On each of these days, animals were administered ip injection of saline and behaviorally tested $10 \mathrm{~min}$ after the injection, and activity counts were recorded using Any Maze software. In Experiment 1, beginning the day following habituation on P33, animals were given an initial ip injection of either an $\alpha 4 \beta 2 \mathrm{nAChR}$ antagonist (dihydro-betaerythroidine $1 \mathrm{mg} / \mathrm{kg}$ or $3 \mathrm{mg} / \mathrm{kg}$ aka DhßE), an a $7 \mathrm{nAChR}$ antagonist (Methyllycaconitine: $2 \mathrm{mg} / \mathrm{kg}$ or $4 \mathrm{mg} / \mathrm{kg}$ aka MLA) or saline before being placed back into the home cage for 10 $\mathrm{min}$ to allow for distribution of the drug. After $10 \mathrm{~min}$, nicotine tartarate $(0.5 \mathrm{mg} / \mathrm{kg}$ free base) or saline was ip administered and animals were placed back into the home cage for another $10 \mathrm{~min}$ to allow for drug distribution. Immediately following this $10 \mathrm{~min}$ period, animals were placed in the locomotor arena, and behavior was recorded for $10 \mathrm{~min}$ on each trial and distance (m) was measured. In Experiment 2, the nAChR antagonists were not administered, and animals were only given nicotine $(0.5 \mathrm{mg} / \mathrm{kg}$ free base). In both experiments, testing was performed every other day for 17 days in all groups resulting in a total of nine days of testing in between the ages of P33 to 49. In both experiments, brain tissue was harvested on P50. In Experiment 1, tissue was analyzed for BDNF, and in Experiment 2, tissue was analyzed for $\mathrm{nAChR}$ binding using the autoradiographic technique.

\section{Experiment 1. BDNF ELISA Procedure}

Twenty-four hours after the last testing session, animals were rapidly decapitated and brain tissue removed. The brain tissue was immediately frozen in cold $\left(-20^{\circ} \mathrm{C}\right)$ isopentane and stored in a $-80^{\circ} \mathrm{C}$ freezer. The nucleus accumbens and dorsal striatum were dissected from each individual brain and then again stored at $-80^{\circ} \mathrm{C}$, and this tissue was used for BDNF analysis. For the ELISA, we followed procedures previously published [20]. In brief, $250 \mu \mathrm{l}$ of RIPA cell lysis buffer (150 mM NaCL, $50 \mathrm{mM}$ Tris-HCl, 1.0\% NP-40, 0.5\% Sodium deoxycholate and $0.1 \%$ SDS) plus protease and phosphatase inhibitors (P5726, P8340, P0044, Sigma-Aldrich, St. Louis, MO) was added to each tissue sample and homogenized using a Fisher Scientific sonic dismembrator 500 (Fisher Scientific, Inc, Atlanta, GA). Homogenates were then centrifuged at $14,000 \mathrm{~g}$ for $20 \mathrm{~min}$ at $4{ }^{\circ} \mathrm{C}$, and the resulting supernatants were refrigerated until the following day when the ELISA was performed. All samples were analyzed according to instructions provided using a BDNF ELISA kit purchased from Promega Scientific (Madison, WI). For the BDNF assay, anti-BDNF monoclonal antibody $(\mathrm{mAb})$ was added to a carbonate coating buffer $(\mathrm{pH} 9.7$, per specifications included with the Promega protocol for BDNF), and $100 \mu$ of the coating buffer was added to each well of a 96-well polystyrene ELISA plate (MaxiSorb, Nalge Nunc International, Rochester, NY) and incubated overnight at $4{ }^{\circ} \mathrm{C}$. All wells were washed using 
wash buffer and incubated at room temperature for $1 \mathrm{~h}$. The BDNF standard curve was prepared using the BDNF standard supplied by the manufacturer $(1 \mu \mathrm{g} / \mathrm{ml})$. The standard was diluted in Block \& Sample $1 \times$ buffer to achieve a concentration range of 0-500 pg/ml. Tissue samples were further diluted 1:2 before being assayed. The standards and samples were incubated with shaking at room temperature for $2 \mathrm{~h}$. Anti-human BDNF pAB was then added to each well plate, incubated at room temperature $(2 \mathrm{~h})$, which was followed by incubation (1 h) with anti-IgY horseradish peroxidase (HRP) conjugate. Visualization was achieved by adding TMB one solution to each well followed by an incubation period of 10 min at room temperature, and this reaction was stopped by adding $1 \mathrm{~N}$ hydrochloric acid to each well and plates were read within 30 min of stopping reaction. Optical density was measured using a Bio-Tek ELx 800 microplate reader (Winooski, VT).

\section{Experiment 2, autoradiography of $\mathrm{nAChRs}$}

After brains were removed, the brain tissue was frozen in isopentane that was chilled in dry ice. Brains were sliced using a Leica CM 3050S cryostat (Nussloch, Germany) to make a series of 20- $\mu \mathrm{m}$ thick sections, which were mounted onto gelatin coated slides. Adjacent sets of sections were prepared to analyze a 7 and a $4 \beta 2 \mathrm{nAChR}$ binding. Alpha a $7 \mathrm{nAChRs}$ were measured using $\mathrm{a}-\left[{ }^{125} \mathrm{I}\right]$-Bungarotoxin autoradiography, as previously described [26,27]. A ligand concentration of $2.5 \mathrm{nmol}\left[{ }^{125} \mathrm{I}\right]$ Tyr54-a-BTX (Perkin-Elmer Life Sciences, Inc., Boston, MA; specific activity $=102.9 \mathrm{Ci} / \mathrm{mmol}$ ) was used for section incubations. For a $4 \beta 2$ nAChRs, total binding density was assessed using [ $\left.{ }^{125} \mathrm{I}\right]$-Epibatidine at a concentration of 500 pM (Perkin-Elmer Life Sciences, Inc., Boston, MA; specific activity 2200Ci/mmol), and nonspecific binding was assessed using both $\left[{ }^{125} \mathrm{I}\right]$-Epibatidine at a concentration of $500 \mathrm{pM}$ and cytisine at a concentration of $100 \mathrm{nM}$. Amersham ECL high performance chemiluminescence film (GE Healthcare, Pollards Wood, UK) was used to visualize the areas of ligand binding. Radioactive rat brain tissue standards were included with each film $\mathrm{X}$-ray cassette in order to determine the response of the film to the increasing amounts of radioactivity. Exposure time was optimized for each ligand: 7 days for [ $\left.{ }^{125} \mathrm{I}\right]-\mathrm{BTX}$, and 30 days for $\left[{ }^{125} \mathrm{I}\right]$-Epibatidine. All films were processed using Kodak D-19 developer.

\section{Quantification of nAChR binding}

Digital images were captured using a light box and Retiga 2000R CCD camera (QImaging, Surrey, BC, Canada). Autoradiograms were quantified with a computer-based image analysis system (MCID Elite software 7.0, Imaging Research, St. Catherine, Ontario, Canada) using calibrated standards of reference (American Radiolabeled Chemicals, St. Louis, MO). Calibration curves against radioligand concentration were constructed using $\left[{ }^{14} \mathrm{C}\right]$ standards of known radioactivity. The reported binding density is the average of radioactivity, determined from the standard, measured across hundreds of pixels located within a defined area of the film (representing the either dorsal striatum or NAcc).

\section{Research Design and Rationale for Dosing}

In Experiment 1, there were three factors in the design: sex (male, female), neonatal drug treatment (quinpirole, saline), and adolescent drug treatment (saline + saline, saline+ nicotine, MLA (two doses) +NIC, Dh $\beta E$ (two doses) +NIC,). Note that there was not a group included in which only the $\mathrm{nAChR}$ antagonist was given followed by saline. The 
rationale for not including these groups was that the focus of the study was to analyze the roles of a 7 and $a 4 \beta 2 \mathrm{nAChR}$ in behavioral sensitization and BDNF response to nicotine in Experiment 1, not the antagonist administered by itself, which would likely produce a completely different response not related to the present focus of the study. The dependent measure for behavioral sensitization was a mean of the distance travelled on day 1 subtracted from the distance travelled on day 9, which was the last day of behavioral sensitization testing. The rationale for this dependent measure was to avoid a four factor design which makes the interpretation of higher-order interactions complex.

A three-way ANOVA was used as the primary statistic and all post hoc comparisons were performed with Newman-Keuls post hoc tests $(\mathrm{p}=0.05)$. The doses chosen for these experiment were based on past work from our laboratory which has shown that a $0.5 \mathrm{mg} / \mathrm{kg}$ dose of NIC produces robust behavioral sensitization in both neonatal saline and quinpirole treated animals, with neonatal quinpirole resulting in enhanced behavioral sensitization to nicotine in adolescence [20]. Both MLA and Dhße were chosen as our nAChR antagonists based on several studies showing that these compounds have been used to effectively test the roles of a 7 and a $4 \beta 2$ nAchRs in both the behavioral [28] and neurochemical effects of nicotine [29,30]. For Experiment 2, there were no antagonists administered, and animals were given the same neonatal drug treatment as Experiment 1, but adolescent drug treatment was either saline or nicotine $(0.5 \mathrm{mg} / \mathrm{kg}$ free base $)$ every second day from P33-49, identical to Experiment 1. In Experiment 2, density of a 7 and a $4 \beta 2$ nAChR binding was the dependent measure, and both the dorsal striatum and nucleus accumbens were analyzed.

\section{Group Coding}

Group codes for neonatal drug treatment are NQ = neonatal quinpirole and NS = neonatal saline. For adolescent drug treatment all animals were given two injections, the first of which was either the antagonist or saline, and the second of which was nicotine or saline. Group codes for adolescent drug treatment are presented with the first drug followed by the second drug in the order they were injected, and include: $\mathrm{SS}=$ saline/saline, $\mathrm{SN}=$ saline/ nicotine, $1 \mathrm{mg} / \mathrm{kg} \mathrm{DN}=1 \mathrm{mg} / \mathrm{kg}$ Dh $\beta \mathrm{E} /$ nicotine, $3 \mathrm{mg} / \mathrm{kg} \mathrm{DN}=3 \mathrm{mg} / \mathrm{kg}$ Dh $\beta \mathrm{E} /$ nicotine, 2 $\mathrm{mg} / \mathrm{kg} \mathrm{MN}=2 \mathrm{mg} / \mathrm{kg}$ MLA/nicotine, and $4 \mathrm{mg} / \mathrm{kg} \mathrm{MN}=4 \mathrm{mg} / \mathrm{kg}$ MLA/nicotine (See Figs. 1-5). Note that in Experiment 2, all groups were given a saline injection followed by either saline or nicotine to mimic the two injection protocol of Experiment 1, thus, in Experiment 2 there are only SS and SN groups represented.

Several statistical analyses were performed. First, an omnibus three-way ANOVA was performed on behavioral sensitization, BDNF levels, and nAChR binding, and simple effects were used to analyze any significant interactions. Further, in Experiment 1 only, we performed a specific comparison (two-way ANOVA) on groups that received either MLA or $\mathrm{Dh} \beta \mathrm{E}$. The rationale for this ANOVA was to compare the function of the $\mathrm{a} 7$ and $\alpha 4 \beta 2$ $\mathrm{nAChR}$ in both behavior and accumbal BDNF in different neonatal drug treatment conditions. Finally, an independent $t$-test was performed to compare NQ and NS rats that received nicotine with no antagonist. The rationale for this comparison was to analyze whether NQ treatment changed the response to nicotine on all dependent measures compared to control animals that also received nicotine. 


\section{Results}

\section{Experiment 1, Behavioral Sensitization}

An initial, two-way ANOVA (sex, neonatal drug treatment) was used to analyze the overall mean of the three habituation trials, and revealed a significant main effect of sex, $\mathrm{F}(1,55)=$ $24.4, \mathrm{p}<0.001$. Females demonstrated an overall increase in activity compared to males, however, this baseline level of activity was not affected by neonatal drug treatment (data not shown). Fig. 1 represents distance travelled as a function of group. A three-way ANOVA revealed significant main effects of sex, $\mathrm{F}(1,176)=16.8$, $\mathrm{p}<0.001$, neonatal drug treatment, $\mathrm{F}(1,176)=17.6, \mathrm{p}<0.001$, adolescent drug treatment $\mathrm{F}(5,176)=32.72$, and a significant interaction of neonatal drug treatment $\times$ adolescent drug treatment, $F(5,176)=4.71, p<$ 0.001 .

The neonatal drug treatment $\times$ adolescent treatment interaction was analyzed through simple effects analyses. Specifically, two separate one-way ANOVAs (adolescent drug treatment) were performed for neonatal drug treatment of saline (NS) and quinpirole (NQ). For NStreated animals, there was a significant main effect of adolescent drug treatment, $\mathrm{F}(5,88)=$ 9.07, $\mathrm{p}<0.011$. Post hoc analyses revealed that NS animals receiving saline followed by nicotine (SN) demonstrated equivalent levels of activity to both MLA-treated groups and the $1 \mathrm{mg} / \mathrm{kg}$ DhßE group, which were significantly greater than all other groups receiving NS. For NQ-treated animals, there was also a significant main effect of adolescent drug treatment, $\mathrm{F}(5,87)=23.34, \mathrm{p}<0.001$. NQ animals receiving saline followed by nicotine (SN) demonstrated significantly higher levels of activity than all other groups. In addition, the NQ groups receiving MLA demonstrated significantly higher levels of activity than both NQ groups receiving Dh $\beta E$ and saline controls. Saline controls and NQ rats that received $\mathrm{Dh} \beta \mathrm{E}$, regardless of dose, did not significantly differ. Finally, an independent groups $t$-test revealed that the NQ group receiving $\mathrm{SN}$ treatment in adolescence demonstrated significantly higher levels of activity than the NS group also receiving SN treatment, $\mathrm{t}(29)=$ $4.37, \mathrm{p}<0.001$. This analysis revealed that indeed NQ enhanced behavioral sensitization to nicotine compared to NS animals. To summarize, NQ produced more robust sensitization to nicotine than controls given nicotine, and $\mathrm{Dh} \beta \mathrm{E}$ was more effective at blocking nicotine sensitization than MLA, however, MLA was less effective in NQ treated groups as compared to NS groups.

A final analysis compared only the groups that received an $\mathrm{nAChR}$ antagonist. The rationale for this analysis was to investigate whether MLA or Dh $\beta E$ resulted in group differences in behavioral sensitization based on neonatal drug treatment. A two-way ANOVA including only NQ and NS groups that received MLA or Dh $\beta E$ revealed significant effects of neonatal drug treatment, $\mathrm{F}(1,118)=4.39, \mathrm{p}<0.03$, adolescent drug treatment, $\mathrm{F}(3,118)=13.82, \mathrm{p}<$ 0.001 , and a significant interaction of neonatal drug treatment $\times$ adolescent drug treatment, $\mathrm{F}(3,118)=3.88, \mathrm{p}<0.011$. Newman-Keuls post hoc comparisons revealed Group NQ animals which received MLA demonstrated significantly greater activity than the NS group that received MLA, regardless of dose. However, NQ and NS animals which received Dh $\beta E$ were equivalent, regardless of dose. This result indicates that a $7 \mathrm{nAChR}$ antagonism was 
less effective to block nicotine sensitization in NQ compared with NS animals, but this was not the case with $\mathrm{Dh} \beta \mathrm{E}$.

\section{Experiment 1, BDNF assay}

An initial three-way ANOVA revealed no significant main effect or interactions of sex, so this factor was dropped from subsequent analyses. A two-way ANOVA (neonatal drug treatment $\times$ adolescent drug treatment) revealed significant main effects of neonatal drug treatment, $\mathrm{F}(1,118)=9.44, \mathrm{p}<0.003$, adolescent drug treatment, $\mathrm{F}(5,118)=33.98, \mathrm{p}<$ 0.001 , and a significant neonatal drug treatment $\times$ adolescent drug treatment interaction, $\mathrm{F}(5,118)=8.22, \mathrm{p}<0.001$. The neonatal drug treatment $\times$ adolescent treatment interaction was analyzed through simple effects analyses. For the NS groups, there was a significant main effect of adolescent drug treatment, $F(5,73)=12.04 p<0.001$. Newman-Keuls post hoc analyses demonstrated that the NS group receiving saline followed by nicotine had significantly higher levels of accumbal BDNF than all other groups. In addition, the NS group receiving saline demonstrated significantly higher levels of accumbal BDNF than all other groups that received either $\mathrm{nAChR}$ antagonist, and the $\mathrm{nAChR}$ antagonist groups did not significantly differ from each other. For the NQ groups, the simple effects analysis also revealed a significant main effect of adolescent drug treatment, $F(5,56)=25.91, p<0.001$. Post hoc analysis demonstrated the NQ group that received saline followed by nicotine was significantly higher than all other groups, which did not significantly differ from each other. Finally, an independent groups $t$-test was utilized to analyze the comparison between SN groups that received NQ or NS neonatal treatment, and similar to behavioral sensitization that analysis was statistically significant, $\mathrm{t}(29)=4.37, \mathrm{p}<001$. NQ enhanced the NAcc BDNF response to nicotine compared to NS treated group given nicotine.

Similar to behavioral sensitization, a final analysis compared only the groups that received an $\mathrm{nAChR}$ antagonist. The rationale for this analysis was to investigate whether MLA or $\mathrm{Dh} \beta \mathrm{E}$ resulted in group differences in BDNF based on neonatal drug treatment. A two-way ANOVA including only NQ and NS groups that received MLA or Dh $\beta E$ revealed only a significant main effect of adolescent drug treatment, $F(3,72)=6.64, p<0.001$. Overall, the highest dose of $\mathrm{Dh} \beta \mathrm{E}$ demonstrated the lowest NAcc BDNF protein compared to all other groups, which did not significantly differ from each other. Therefore, unlike behavioral sensitization, the change in BDNF relative to $\mathrm{nAChR}$ antagonist treatment did not significantly differ based on neonatal drug treatment.

\section{Experiment 2, Behavioral Sensitization}

An initial two-way ANOVA (sex, neonatal drug treatment) of the mean activity during habituation revealed a significant main effect of sex, $(F 1,48)=6.5, p<0.02$. Similar to the results of Experiment 1, females demonstrated an overall increase in activity as compared to males (data not shown). The main effect of neonatal drug treatment and the interaction were not significant.

With respect to behavioral sensitization, the three-way ANOVA ( $\operatorname{sex} \times$ neonatal drug treatment $\times$ adolescent drug treatment) did not reveal a significant main effect or interactions of sex, so this factor was dropped from subsequent analyses. A two-way ANOVA (neonatal 
drug treatment $\times$ adolescent drug treatment) revealed significant main effects of neonatal drug treatment, $\mathrm{F}(1,48)=12.27, \mathrm{p}<0.001$, adolescent drug treatment, $\mathrm{F}(1,48)=57.05$, $\mathrm{p}<$ 0.001 , and a significant interaction of neonatal drug treatment $\times$ adolescent drug treatment, $F(1,48)=5.18, p<0.028$. Based on the comparison of only four groups and to simplify the analysis, simple effects were not used and a Newman-Keuls post hoc test was used to reveal that NQ group receiving $\mathrm{SN}$ treatment was significantly greater than all other groups. In addition, the NQ group receiving SN treatment was significantly greater than saline-treated groups, which did not significantly differ from each other. Essentially, these results replicate the effect observed in Experiment 1 and those of Perna \& Brown [20] showing that NQ results in enhanced behavioral sensitization to nicotine.

\section{Experiment 2, Autoradiographic analyses of nAChR density}

Density of receptor binding is represented as nanocuries per milligram of tissue $(\mathrm{nCI} / \mathrm{mg})$ for $\left[{ }^{125} \mathrm{I}\right]$ alpha-bungarotoxin (a $7 \mathrm{nAChRs}$ ) and [ ${ }^{125} \mathrm{I}$ epibatidine (a $4 \beta 2 \mathrm{nAChRs}$ ) in Fig. $4 \mathrm{a}$ and $b$, respectively. As with other analyses, no significant main effect or interactions were revealed with sex as a factor, regardless of the ligand analyzed or brain area (although it should be noted only 3-4 males and females were used in each drug condition). Therefore, a two-way ANOVA (neonatal drug treatment $\times$ adolescent drug treatment) was used for each a 7 and $\alpha 4 \beta 2 \mathrm{nAChRs}$ with a total $\mathrm{N}$ of $6-7$ per drug condition per brain area. For a 7 binding in the NAcc, a two-way ANOVA revealed a significant main effect of adolescent drug treatment, $F(1,25)=6.64, p<0.017$ and a significant interaction of neonatal drug treatment $\times$ adolescent drug treatment, $F(1,25)=6.80, p<0.016$. Post hoc analyses revealed that the NS group receiving SN treatment demonstrated a significant increase of a $7 \mathrm{nAChR}$ binding in the NAcc relative to the other three groups, which did not significantly differ from each other. Therefore, NQ appears to have blocked the increase of a 7 binding in the NAcc. In the dorsal striatum, a two-way ANOVA also revealed a significant interaction of neonatal drug treatment $\times$ adolescent drug treatment, $F(1,27)=4.47, p<0.045$. Post hoc analyses revealed that both the NS group receiving SN and the NQ group receiving SS were equivalent, and both demonstrated significantly increased a 7 binding compared to NS receiving SS and NQ receiving SN. Similar to the NAcc, NQ appears to have blocked increased $a 7$ binding in the dorsal striatum, however, NQ significantly increased $a 7$ binding in the dorsal striatum in animals given saline, a finding that replicates past work by Tizabi et al. [31].

Regarding [125I] epibatidine binding in the NAcc, a two-way ANOVA revealed significant main effects of neonatal drug treatment, $\mathrm{F}(1,26)=17.84, \mathrm{p}<0.001$, adolescent drug treatment, $\mathrm{F}(1,26)=71.31, \mathrm{p}<0.001$, and a significant interaction of neonatal drug treatment $\times$ adolescent drug treatment, $F(1,26)=9.72, p<0.001$. Post hoc analyses revealed a robust significant increase of $\left[{ }^{125} \mathrm{I}\right]$ epibatidine binding in the NQ group receiving SN compared all other groups. In addition, the NS group receiving $\mathrm{SN}$ demonstrated a significant increase in $\left[{ }^{125} \mathrm{I}\right]$ epibatidine binding compared to both groups receiving saline, and the latter two groups did not differ significantly. In the dorsal striatum, there were no significant main effects or interaction revealed. Interestingly, changes in a $4 \beta 2 \mathrm{nAChRs}$ appear to be directed toward the NAcc. 


\section{Discussion}

This study revealed several key findings relative to nicotine's effects on behavioral sensitization, accumbal BDNF, and changes in a 7 and $\alpha 4 \beta 2 \mathrm{nAChRs}$ in the NAcc and dorsal striatum in the NQ model. Replicating previous work [18,20], both experiments demonstrated that NQ robustly enhanced behavioral sensitization to nicotine in adolescent animals. With increased dopamine $\mathrm{D}_{2}$ receptor sensitivity that is present in the NQ model, the current findings have implications regarding the differential roles of nAChRs and BDNF in the behavioral response to nicotine under the conditions of increased dopaminergic signaling. Specifically, it was discovered that the a $4 \beta 2$ receptor appears to play a more prominent role in the induction of the behavioral sensitization to nicotine than does the a 7 nAChR, based on the result that both NQ and NS animals that received either dose of the a $4 \beta 2 \mathrm{nAChR}$ antagonist $\mathrm{Dh} \beta \mathrm{E}$ demonstrated significantly lower activity levels than animals administered the $a 7$ antagonist MLA or saline. This finding supports past work that has shown that in general, the a $4 \beta 2 \mathrm{nAChR}$ has been found to play a more prominent role in the behavioral sensitization to nicotine [32]. However, no previous work has analyzed the differential role of these two nAChRs in adolescent nicotine sensitization. Further, Tapper et al. [33] demonstrated that activation of a $4 \mathrm{nAChRs}$ was sufficient for nicotine-induced reward, tolerance, and sensitization. The findings here extend this previous work toward a model of dopamine $\mathrm{D}_{2}$ supersensitivity with implications towards schizophrenia.

An important discovery is that NQ produced an identical pattern of enhanced BDNF response to nicotine and a $4 \beta 2 \mathrm{nAChR}$ upregulation in the NAcc. BDNF has also been shown to be important in the brain's reward pathways [see 34 for review], and accumbal BDNF and its receptor tyrosine kinase B (trkB)interactions in the NAcc have been shown to play a critical role in behavioral processes directly related to addiction [35-37]. The present study extends these previous findings, demonstrating that NQ treatment, which increases sensitivity of the dopamine $\mathrm{D}_{2}$ receptor, enhanced sensitization to nicotine in adolescence as well as the accumbal BDNF response and $a 4 \beta 2 \mathrm{nAChR}$ binding relative to all other groups. In NS animals, nicotine produced a significant increase in both BDNF and a $4 \beta 2 \mathrm{nAChRs}$ compared to controls. This finding, coupled with the fact that these changes are occuring during adolescence when tobacco smoking often initiates, underlines the relevance of this result. Further, there is strong evidence in research on nicotine dependence that supports genetic associations of the $\mathrm{a} 4 \mathrm{nAChR}$ subunit (CHRNA4) with tyrosine kinase B (TrkB; NTRK2), which is the receptor to which BDNF binds [38-41]. Therefore, it appears that not only may there be an existing relationship between $\alpha 4 \beta 2$ nAChRs and BDNF, especially in the NAcc, but this relationship is also observed in NQ-treated rats, a model of dopamine $\mathrm{D}_{2}$ receptor supersensitivity with relevance to schizophrenia.

It is important to point out that there was no differential behavioral response to either $\mathrm{nAChR}$ antagonist due to neonatal drug treatment. One issue here may be that the changes reported in nAChR binding density may not be a good indicator of nAChR activity, or that changes in nAChR density within the NAcc may not be related to behavioral sensitization. However, past work has demonstrated that accumbal infusion of nAChR antagonists blocked increases in dopamine release in the NAcc and accumbal dopamine activity has been shown to mediate the behavioral effects of nicotine $[42,43]$. Another potential issue is that these 
$\mathrm{nAChR}$ antagonists were administered over an 18-day period, every second day, during adolescence. How this subchronic treatment of nAChR antagonists affected receptor density and/or nAChR sensitivity is unknown, which may also play a role in the behavioral results observed in the present study.

Interestingly, the common smoking cessation treatment, varenicline (Trade name: Chantix), which is a partial agonist at the $a 4 \beta 2 \mathrm{nAChR}$, has been generally shown to be effective for smoking cessation in populations diagnosed with psychosis [44], and the more robust upregulation of a $4 \beta 2 \mathrm{nAChR}$ density in NQ animals observed in the present study is consistent with this outcome. Past work has shown that there is a complex interaction between dopamine $D_{2}$ receptors and a $4 \beta 2 \mathrm{nAChRs}$ in the striatum, with a $4 \mathrm{nAChRs}$ and dopamine $\mathrm{D}_{2}$ receptors both co-localized on cholinergic interneurons. Research has shown that when dopamine levels decrease, it results in disinhibition of these cholinergic interneurons [45-47]. Likewise, nicotine results in inhibition of these cholinergic interneurons in the dorsal striatum [48]. If dopamine $\mathrm{D}_{2}$ receptors are increased in their sensitivity and the dopamine system is activated by nicotine, it may contribute to further inhibition of these interneurons. For example, findings have shown that application of nicotine in striatal slices inhibits cholinergic interneurons and conversely, blockade of nAChRs increases burst firing [48]. In a system with increased sensitivity of dopamine $\mathrm{D}_{2}$ receptors, nicotine may result in possible silencing of cholinergic interneurons with the combined activation of a $4 \beta 2$ nAChRs through nicotine's agonist action and increased sensitivity of dopamine $\mathrm{D}_{2}$ receptors of these interneurons, which may contribute to increased burst firing. Ultimately, this may result in significant increases of dopamine in response to nicotine in NQ-treated rats [20]. More research on this mechanism will be a focus of future work.

Interestingly, a completely different pattern emerged for the effects of NQ on a $7 \mathrm{nAChR}$ density after nicotine treatment, including NQ resulting in an a $7 \mathrm{nAChR}$ downregulation in the NAcc in response to nicotine. Past work has shown that dopamine $\mathrm{D}_{2}$ and $\mathrm{a} 7 \mathrm{nAChRs}$ are co-localized on many of the same postsynaptic dendrites and astrocytes in the prefrontal cortex [49], as well as the same neurons in the ventral tegmental area (VTA) [50]. Of course, the VTA is located in the midbrain and sends major dopaminergic projections to both the prefrontal cortex and NAcc, and both pathways have been strongly implicated in addiction. Garzon and colleagues [50] suggest that antipsychotic drugs, all of which block the dopamine $\mathrm{D}_{2}$ receptor with some affinity [51], may act in the VTA to facilitate a $7 \mathrm{nAChR}$ burst firing by elimination of $\mathrm{D}_{2}$ receptor inhibition in neurons expressing both receptors. This may actually work the opposite in the present case, because dopamine $\mathrm{D}_{2}$ receptors are increased in their sensitivity. That is, we found that NQ rats that received saline resulted in a significant upregulation of $\mathrm{a} 7 \mathrm{nAChRs}$ in the striatum at P50, supporting past data from Tizabi and colleagues [31] that found a $7 \mathrm{nAChRs}$ are upregulation in the striatum at P30 after NQ treatment (identical to the treatment given in the present study). However, when nicotine was administered subchronically, a $7 \mathrm{nAChRs}$ were found to be down-regulated in the NAcc. We suspect that this downregulation may be due to colocalization of dopamine $\mathrm{D}_{2}$ receptors and a $7 \mathrm{nAChRs}$, and when nicotine is administered, it acts to inhibit the supersensitized dopamine $\mathrm{D}_{2}$ autoreceptor [52], increasing activation of the dopamine system and ultimately resulting in a downregulation, or possibly, densensitization of 
accumbal a 7 nAChRs. While this is speculative, it has been established that increases of dopamine activation, similar to what occurs in schizophrenia, ultimately results in a downregualtion of a $7 \mathrm{nAChRs}$ [53]. However, there are no reports on changes in the a 7 $\mathrm{nAChR}$ in brain areas mediating drug reward, nor is there any data on the density of nAChRs in brain reward areas during the adolescent period. Further, the characteristics of $n A C h R s$ in reward areas of the brain in schizophrenic smokers is also unknown.

Past work has established a relationship between both a 7 and a $4 \beta 2$ nAChRs and BDNF in different brain regions. For example, it has been shown that BDNF can lead to upregulation of a 7 nAChRs on hippocampal interneurons [54], and chronic mecamylamine, a noncompetitive $\mathrm{nAChR}$ antagonist, reduced BDNF in the pre-frontal cortex [55]. Nicotine directly injected into the hippocampus also resulted in an increased in BDNF mRNA [56], and chronic, but not acute, nicotine has been shown to increase hippocampal BDNF [57]. Therefore, it was not necessarily surprising that both MLA and DhBE resulted in a significant decrease of accumbal BDNF, but there were no significant group differences between the two antagonists used. This suggests that there is a close relationship between BDNF and nAChRs, and antagonism of either a 7 or a $4 \beta 2 \mathrm{nAChRs}$ is sufficient to produce a significant decrease of BDNF in brain areas that mediate drug reward.

Antagonism of a $7 \mathrm{nAChR}$ with MLA failed to block nicotine sensitization in both NQ and NS animals, however, it was more effective in NS-treated animals. On the other hand, antagonism of the a $4 \beta 2$ completely blocked nicotine sensitization in both NQ and NStreated animals, and there were no significant differences between these groups based on neonatal drug treatment. Importantly, these two nAChRs have not been directly compared in behavioral sensitization to nicotine when an antagonist was administered each day of nicotine administration as was done in the present study. Furthermore, there have not been any studies that have analyzed the relationship between nAChRs and behavioral sensitization to nicotine exposure in adolescence, so this is the first study to analyze nAChRs during this critical period in which nicotine addiction often begins [58]. The fact that MLA was less effective in NQ animals, but NQ animals in Experiment 2 demonstrated downregulation of a 7 nAChRs compared NS-treated rats was somewhat surprising. It may be that the $\mathrm{D}_{2}$ supersensitization that is produced by neonatal quinpirole treatment not only produces downregulation of a 7 naChRs, but may also reduce their sensitivity to antagonism. Our hypothesis is that the upregulation of dorsal striatum a $7 \mathrm{nAChRs}$ produced by NQ treatment may be important in the initial response to nicotine in NQ rats, but as nicotine is continually administered, a $4 \beta 2 \mathrm{nAChRs}$ play a more prominent role in the behavioral response to nicotine. Supporting this idea, past work has shown that chronic nicotine selectively upregulates $\alpha 4 \beta 2$ nAChRs in the nigrostriatal pathway as well as enhanced MLA-resistant nicotinic currents in substantia nigra GABA neurons [59] in both slice and intact mice. This would support the hypothesis that as nicotine is sub-chronically administered, the a $4 \beta 2$ $\mathrm{nAChR}$ is critical in nicotine sensitization in both NQ and NS-treated rats.

In conclusion, the present study characterizes the relationship of behavioral sensitization to nicotine and BDNF and two prominent nAChRs in a model of dopamine $\mathrm{D}_{2}$ receptor supersensitivity during adolescence, a critical period of development for not only the dopamine system [60] but also for the initiation of smoking behavior. Future work is aimed 
at more fully analyzing the neural plasticity response to nicotine in adolescence, sex differences that may exist, and mechanisms downstream from BDNF that may lead to the discovery of pharmacological targets for smoking cessation in schizophrenia and psychosis.

\section{Acknowledgments}

The authors would like to thank James D. Wherry for his help in behavioral testing, and the contributions of Daniel J. Peterson's doctoral thesis committee: Matthew I. Palmatier, Richard M. Kostrzewa, Eric W. Sellers, and Jon R. Webb. The work contained in this manuscript was in partial fulfillment of Daniel J. Peterson's doctoral dissertation submitted to East Tennessee State University Department of Psychology.

This study was supported by NIH 1R15DA034912-A1 to RWB.

\section{References}

1. Lohr JB, Flynn K. Smoking and schizophrenia. Schizophrenia Res. 1992; 8(2):93-102.

2. Williams JM, Gandhi KK, Lu SE, Kumar S, Steinberg ML, Cottler B, Benowitz NL. Shorter interpuff interval is associated with higher nicotine intake in smokers with schizophrenia. Drug Alcohol Depend. 2011; 118(2):313-319. [PubMed: 21596491]

3. Weinberger AH, Sacco KA, Creeden CL, Vessicchio JC, Jatlow PI, George TP. Effects of acute abstinence, reinstatement, and mecamylamine on biochemical and behavioral measures of cigarette smoking in schizophrenia. Schizophrenia Res. 2007; 91(1):217-225.

4. Williams JM, Ziedonis DM, Abanyie F, Steinberg ML, Foulds J, Benowitz NL. Increased nicotine and cotinine levels in smokers with schizophrenia and schizoaffective disorder is not a metabolic effect? Schizophrenia Res. 2005; 79(2):323-335.

5. Kostrzewa RM, Hamdi A, Kostrzewa FP. Production of prolonged supersensitization of dopamine D2 receptors? Eur J Pharm. 1990; 183(4):1411-1412.

6. Seeman P. An update of fast-off dopamine D2 atypical antipsychotics? Am J Psychiatry. 2005; 162(10):1984-1985.

7. Seeman P. All roads to schizophrenia lead to dopamine supersensitivity and elevated dopamine D2High receptors? CNS Neurosci Ther. 2011; 17(2):118-132. [PubMed: 20560996]

8. Brown RW, Maple AM, Perna MK, Sheppard AB, Cope ZA, Kostrzewa RM. Schizophrenia and substance abuse comorbidity: nicotine addiction and the neonatal quinpirole model? Dev Neurosci. 2012; 34(2-3):140-151. [PubMed: 22777523]

9. Balu DT. The NMDA receptor and schizophrenia: from pathophysiology to treatment. Adv Pharmacol. 2016; 76:351-382. [PubMed: 27288082]

10. Thacker SK, Perna MK, Ward JJ, Schaefer TL, Williams MT, Kostrzewa RM, Brown RW. The effects of adulthood olanzapine treatment on cognitive performance and neurotrophic factor content in male and female rats neonatally treated with quinpirole. Eur J Neurosci. 2006; 24:20752083. [PubMed: 17067304]

11. Maple AM, Smith KJ, Perna MK, Brown RW. Neonatal quinpirole treatment produces prepulse inhibition deficits in adult male and female rats. Pharmacol Biochem Behav. 2015; 137:93-100. [PubMed: 26296939]

12. Brown RW, Perna MK, Schaefer TL, Williams MT. The effects of adulthood nicotine treatment on D2-mediated behavior and neurotrophins of rats neonatally treated with quinpirole. Synapse. 2006; 59:253-259. [PubMed: 16408261]

13. Maple AM, Perna MK, Parlaman JP, Stanwood GD, Brown RW. Ontogenetic quinpirole treatment produces long-lasting decreases in the expression of Rgs9, but increases Rgs17 in the striatum, nucleus accumbens and frontal cortex. Eur J Neurosci. 2007; 26:2532-2538. [PubMed: 17970732]

14. Segal DS, Mandell AJ. Long-term administration of d-amphetamine: progressive augmentation of motor activity and stereotypy? Pharm Biochem Behav. 1974; 2(2):249-255.

15. Pierce RC, Kalivas PW. A circuitry model of the expression of behavioral sensitization to amphetamine-like psychostimulants? Brain Res Rev. 1997; 25(2):192-216. [PubMed: 9403138] 
16. Vanderschuren LJ, Kalivas PW. Alterations in dopaminergic and glutamatergic transmission in the induction and expression of behavioral sensitization: a critical review of preclinical studies. Psychopharmacology (Berl). 2000; 151(2-3):99-120. [PubMed: 10972458]

17. Harrod SB, Mactutus CF, Bennett K, Hasselrot U, Wu G, Welch M, Booze RM. Sex differences and repeated intravenous nicotine: behavioral sensitization and dopamine receptors. Pharm Biochem Behav. 2004; 78(3):581-592.

18. Sheppard B, Lehmann J, Cope ZA, Brown RW. Sex differences in nicotine sensitization and conditioned hyperactivity in adolescent rats neonatally treated with quinpirole: role of D2 and D3 receptor subtypes? Behav Neurosci. 2009; 123(6):1296-1302. [PubMed: 20001113]

19. Perna MK, Cope ZA, Maple AM, Longacre ID, Correll JA, Brown RW. Nicotine sensitization in adult male and female rats quinpirole-primed as neonates. Psychopharmacology (Berl). 2008; 199(1):67-75. [PubMed: 18548235]

20. Perna MK, Brown RW. Adolescent nicotine sensitization and effects of nicotine on accumbal dopamine release in a rodent model of increased dopamine D2 receptor sensitivity. Behav Brain Res. 2013; 242:102-109. [PubMed: 23291224]

21. Mao D, McGehee DS. Nicotine and behavioral sensitization. J Mol Neurosci. 2010; 40(1-2):154163. [PubMed: 19669944]

22. Pickens CL, Airavaara M, Theberge F, Fanous S, Hope BT, Shaham Y. Neurobiology of the incubation of drug craving. Trends Neurosci. 2011; 34(8):411-420. [PubMed: 21764143]

23. Lydon DM, Wilson SJ, Child A, Geier CF. Adolescent brain maturation and smoking: what we know and where we're headed. Neurosci Biobehav Rev. 2014; 45:323-342. [PubMed: 25025658]

24. Walters CL, Brown S, Changeux JP, Martin B, Damaj MI. The beta2 but not alpha7 subunit of the nicotinic acetylcholine receptor is required for nicotine-conditioned place preference in mice. Psychopharmacology (Berl). 2006; 184(3-4):339-344. [PubMed: 16416156]

25. Smith RF. Animal models of periadolescent substance abuse. Neurotoxicol Teratol. 2003; 25(3): 291-301. [PubMed: 12757826]

26. Sparks JA, Pauly JR. Effects of continuous oral nicotine administration on brain nicotinic receptors and responsiveness to nicotine in C57B1/6 mice. Psychopharmacology (Berl). 1999; 141(2):145153. [PubMed: 9952038]

27. Gueseva MV, Hopkins DM, Pauly JR. An autoradiographic analysis of rat brain nicotinic receptor plasticity following dietary choline modification. Pharmacol Biochem Behav. 2006; 84(1):26-34. [PubMed: 16753203]

28. Hahn B, Shoaib M, Stolerman IP. Selective nicotinic receptor antagonists: effects on attention and nicotine-induced attentional enhancement. Psychopharmacology. 2011; 217:75-82. [PubMed: 21432025]

29. Fu Y, Matta SG, Gao W, Sharp BM. Local alpha-bungarotoxin-sensitive nicotinic receptors in the nucleus accumbens modulate nicotine-stimulated dopamine secretion in vivo. Neuroscience. 2000; 101(2):369-375. [PubMed: 11074160]

30. Livingstone PD, Srinivasan J, Kew JN, Dawson LA, Gotti C, Moretti M, Shoaib M, Wonnacott S. alpha7 and non-alpha7 nicotinic acetylcholine receptors modulate dopamine release in vitro and in vivo in the rat prefrontal cortex. Eur J Neurosci. 2009; 29(3):539-550. [PubMed: 19187266]

31. Tizabi Y, Copeland RL Jr, Brus R, Kostrzewa RM. Nicotine blocks quinpirole-induced behavior in rats: psychiatric implications. Psychopharmacology (Berl). 1999; 145(4):433-441. [PubMed: 10460321]

32. Kempsill FE, Pratt JA. Mecamylamine but not the alpha7 receptor antagonist alpha-bungarotoxin blocks sensitization to the locomotor stimulant effects of nicotine. Br J Pharmacol. 2000; 131(5): 997-1003. [PubMed: 11053222]

33. Tapper AR, McKinney SL, Nashmi R, Schwarz J, Deshpande P, Labarca C, Whiteaker P, Marks MJ, Collins AC, Lester HA. Nicotine activation of alpha4* receptors: sufficient for reward, tolerance, and sensitization. Science. 2004; 306(5698):1029-1032. [PubMed: 15528443]

34. Thomas MJ, Kalivas PW, Shaham Y. Neuroplasticity in the mesolimbic dopamine system and cocaine addiction. Br J Pharmacol. 2008; 154(2):327-342. [PubMed: 18345022] 
35. Ren Q, Ma M, Yang C, Zhang JC, Yao W, Hashimoto K. BDNF-TrkB signaling in the nucleus accumbens shell of mice has key role in methamphetamine withdrawal symptoms. Transl Psychiatry. 2015; 5:e666. [PubMed: 26506052]

36. McGinty JF, Zelek-Molik A, Sun WL. Cocaine self-administration causes signaling deficits in corticostriatal circuitry that are reversed by BDNF in early withdrawal. Brain Res. 2015; 1628:8287. [PubMed: 25268928]

37. Leão RM, Cruz FC, Carneiro-de-Oliveira PE, Rossetto DB, Valentini SR, Zanelli CF, Planeta CS. Enhanced nicotine-seeking behavior following pre-exposure to repeated cocaine is accompanied by changes in BDNF in the nucleus accumbens of rats. Pharmacol Biochem Behav. Mar.2013 104:169-176. [PubMed: 23333681]

38. Li MD, Beuten J, Ma JZ, Payne TJ, Lou XY, Garcia V, Duenes AS, Crews KM, Elston RC. Ethnicand gender-specific association of the nicotinic acetylcholine receptor alpha4 subunit gene (CHRNA4) with nicotine dependence. Hum Mol Genet. 2005; 14:1211-1219. [PubMed: 15790597]

39. Feng Y, Niu T, Xing H, Xu X, Chen C, Peng S, Wang L, Xu X. A common haplotype of the nicotine acetylcholine receptor alpha 4 subunit gene is associated with vulnerability to nicotine addiction in men. Am J Hum Genet. 2004; 75:112-121. [PubMed: 15154117]

40. Beuten J, Ma JZ, Payne TJ, Dupont RT, Lou XY, Crews KM, Elston RC, Li MD. Association of specific haplotypes of neurotrophic tyrosine kinase receptor 2 gene (NTRK2) with vulnerability to nicotine dependence in African-Americans and European-Americans. Biol Psychiatry. 2007; 61:48-55. [PubMed: 16713586]

41. Hutchison KE, Allen DL, Filbey FM, Jepson C, Lerman C, Benowitz NL, Stitzel J, Bryan A, McGeary J, Haughey HM. CHRNA4 and tobacco dependence: from gene regulation to treatment outcome. Arch Gen Psychiatry. 2007; 64:1078-1086. [PubMed: 17768273]

42. Brunzell DH, Boschen KE, Hendrick ES, Beardsley PM, McIntosh JM. Alpha-conotoxin MIIsensitive nicotinic acetylcholine receptors in the nucleus accumbens shell regulate progressive ratio responding maintained by nicotine. Neuropsychopharmacology. 2010; 5(3):665-673.

43. Gotti C, Guiducci S, Tedesco V, Corbioli S, Zanetti L, Moretti M, Zanardi A, Rimondini R, Mugnaini M, Clementi F, Chiamulera C, Zoli M. Nicotinic acetylcholine receptors in the mesolimbic pathway: primary role of ventral tegmental area alpha6beta $2 *$ receptors in mediating systemic nicotine effects on dopamine release, locomotion, and reinforcement. J Neurosci. 2010; 30(15):5311-5325. [PubMed: 20392953]

44. Smith RC, Amiaz R, Si TM, Maayan L, Jin H, Boules S, Sershen H, Li C, Ren J, Liu Y, Youseff M, Lajtha A, Guidotti A, Weiser M, Davis JM. Varenicline effects on smoking, cognition, and psychiatric symptoms in schizophrenia: a double-blind randomized trial. PLoS One. 2016; 11(1):e0143490. [PubMed: 26730716]

45. Pisani A, Martella G, Tscherter A, Bonsi P, Sharma N, Bernardi G, Standaert DG. Altered responses to dopaminergic D2 receptor activation and $\mathrm{N}$-type calcium currents in striatal cholinergic interneurons in a mouse model of DYT1 dystonia. Neurobiol Dis. 2006; 24:318-325. [PubMed: 16934985]

46. Alcantara AA, Chen V, Herring BE, Mendenhall JM, Berlanga ML. Localization of dopamine D2 receptors on cholinergic interneurons of the dorsal striatum and nucleus accumbens of the rat. Brain Res. 2003; 986:22-29. [PubMed: 12965226]

47. Yan Z, Song WJ, Surmeier J. D2 dopamine receptors reduce N-type Ca2+ currents in rat neostriatal cholinergic interneurons through a membrane-delimited, protein-kinase-C-insensitive pathway. $\mathrm{J}$ Neurophysiol. 1997; 77:1003-1015. [PubMed: 9065864]

48. De Rover M, Lodder JC, Kits KS, Schoffelmeer AN, Brussaard AB. Cholinergic modulation of nucleus accumbens medium spiny neurons. Eur J Neurosci. 2002; 16:2279-2290. [PubMed: 12492422]

49. Duffy AM, Fitzgerald ML, Chan J, Robinson DC, Milner TA, Mackie K, Pickel VM. Acetylcholine a 7 nicotinic and dopamine D2 receptors are targeted to many of the same postsynaptic dendrites and astrocytes in the rodent prefrontal cortex. Synapse. $2011 ; 65(12): 1350$ 1367. [PubMed: 21858872] 
50. Garzón M, Duffy AM, Chan J, Lynch MK, Mackie K, Pickel VM. Dopamine D2 and acetylcholine a 7 nicotinic receptors have subcellular distributions favoring mediation of convergent signaling in the mouse ventral tegmental area. Neuroscience. 2013; 252:126-143. [PubMed: 23954803]

51. Seeman P. Dopamine D2 receptors as treatment targets in schizophrenia. Clin Schizophr Relat Psychoses. 2010; 4(1):56-73. [PubMed: 20643630]

52. Harsing LG Jr, Sershen H, Lajtha A. Dopamine efflux from striatum afterchronic nicotine: evidence for autoreceptor desensitization. J Neurochem. 1992; 59(1):48-54. [PubMed: 1351932]

53. Olincy A, Freedman R. Nicotinic mechanisms in the treatment of psychotic disorders: a focus on the a 7 nicotinic receptor. Handb Exp Pharmacol. 2012; 213:211-232.

54. Massey KA, Zago WM, Berg DK. BDNF up-regulates alpha7 nicotinic acetylcholine receptor levels on subpopulations of hippocampal interneurons. Mol Cell Neurosci. 2006; 33(4):381-388. [PubMed: 17029981]

55. Aboul-Fotouh S. Behavioral effects of nicotinic antagonist mecamylamine in arat model of depression: prefrontal cortex level of BDNF protein and monoaminergic neurotransmitters. Psychopharmacology (Berl). 2015; 232(6):1095-1105. http://dx.doi.org/10.1007/ s00213-014-3745-5. [PubMed: 25315361]

56. French SJ, Humby T, Horner CH, Sofroniew MV, Rattray M. Hippocampal neurotrophin and trk receptor mRNA levels are altered by local administration of nicotine, carbachol and pilocarpine. Brain Res Mol Brain Res. 1999; 67(1):124-136. [PubMed: 10101239]

57. Kenny PJ, File SE, Rattray M. Acute nicotine decreases, and chronic nicotine increases the expression of brain-derived neurotrophic factor mRNA in rathippocampus. Brain Res Mol Brain Res. 2000; 85(1-2):234-238. [PubMed: 11146126]

58. Holliday E, Gould TJ. Nicotine, adolescence, and stress: a review of how stress can modulate the negative consequences of adolescent nicotine abuse. Neurosci Biobehav Rev. 2016; 65:173-184. [PubMed: 27068856]

59. Xiao C, Nashmi R, McKinney S, Cai H, McIntosh JM, Lester HA. Chronic nicotine selectively enhances alpha4beta2* nicotinic acetylcholine receptors in thenigrostriatal dopamine pathway. $\mathrm{J}$ Neurosci. 2009; 29(40):12428-12439. [PubMed: 19812319]

60. Andersen SL, Teicher MH. Sex differences in dopamine receptors and theirrelevance to ADHD. Neurosci Biobehav Rev. 2000; 24(1):137-141. [PubMed: 10654670] 


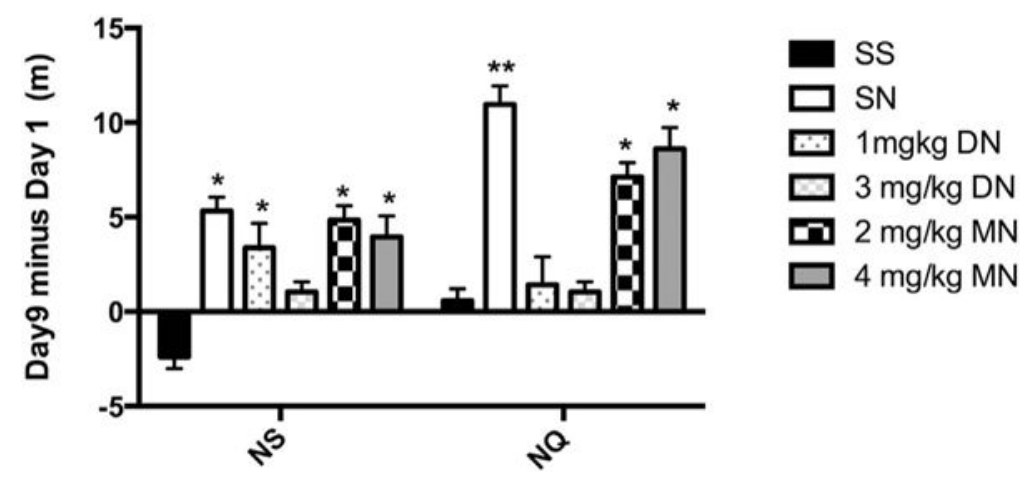

Fig. 1.

The difference in distance traveled is presented as a function of neonatal drug treatment (xaxis) and adolescent drug treatment (legend) for behavioral sensitization in Experiment 1. Group NQ administered SN demonstrated significantly higher distance traveled during behavioral sensitization than all other groups (indicated by $* *, p<0.05$ ). All groups given nicotine with the exception of the NS groups administered $3 \mathrm{mg} / \mathrm{kg}$ DN and both NQ DN groups demonstrated significantly greater distance traveled during behavioral sensitization than controls (Group NS administered SS; indicated by *, p < 0.05). 


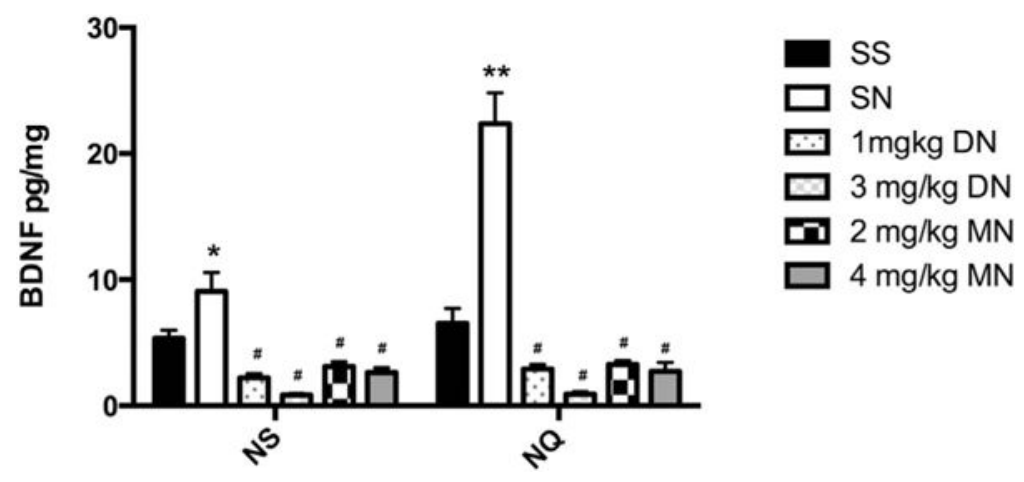

Fig. 2.

NAcc BDNF (pg/mg) protein is presented as a function neonatal drug treatment ( $\mathrm{x}$-axis) and adolescent drug treatment (legend). Group NQ administered SN demonstrated significantly higher BDNF protein levels in the NAcc than all other groups (indicated by **, p < 0.05 ). Group NS administered SN demonstrated significantly higher BDNF protein levels in the NAcc than controls (Group NS and NQ administered SS) and all groups given an antagonist (indicated by $*, \mathrm{p}<0.05)$. All antagonist groups demonstrated significantly lower NAcc BDNF protein levels than controls (indicated by \#, $\mathrm{p}<0.05$ ). 


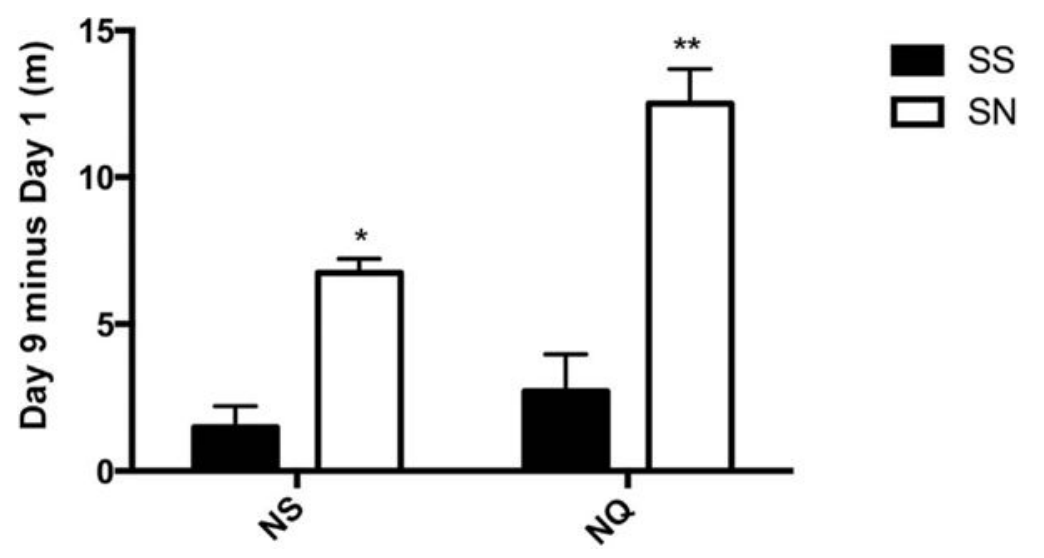

Fig. 3.

The difference in distance traveled is presented as a function of neonatal drug treatment ( $\mathrm{x}-$ axis) and adolescent drug treatment (legend) for behavioral sensitization in Experiment 2. Group NQ administered SN demonstrated significantly higher distance traveled than all other groups (indicated by **, p < 0.05). NS Group administered SN demonstrated significantly higher distance traveled than controls (Group NS and Group NQ administered $\mathrm{SS}$; indicated by $*, \mathrm{p}<0.05)$. 

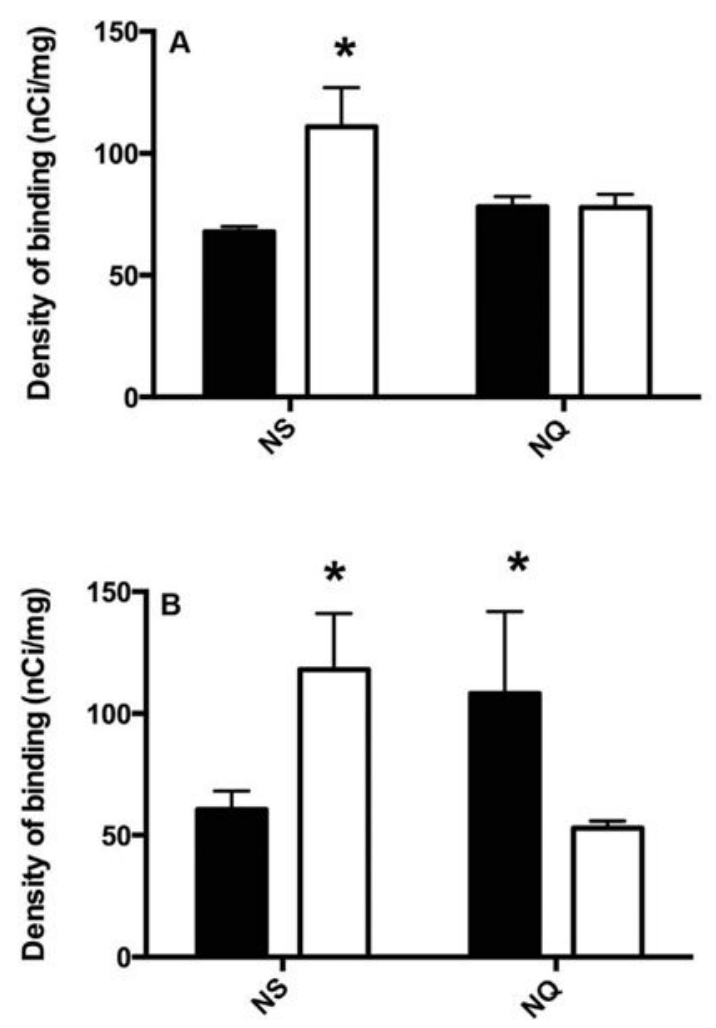

Fig. 4.

The density of binding $(\mathrm{nCi} / \mathrm{mg})$ is presented as a function of neonatal drug treatment ( $\mathrm{x}-$ axis) and adolescent drug treatment (legend) a $7 \mathrm{nAChR}$ binding in the NAcc (A) and dorsal striatum (B). In the NAcc, NS administered SN demonstrated significantly higher a 7 $\mathrm{nAChR}$ binding than all other groups (indicated by $*, \mathrm{p}<0.05$ ). In the dorsal striatum, Group NS and Group NQ administered SS were equivalent and demonstrated significantly higher BDNF protein levels than the other groups (indicated by $*, p<0.05$ ). 

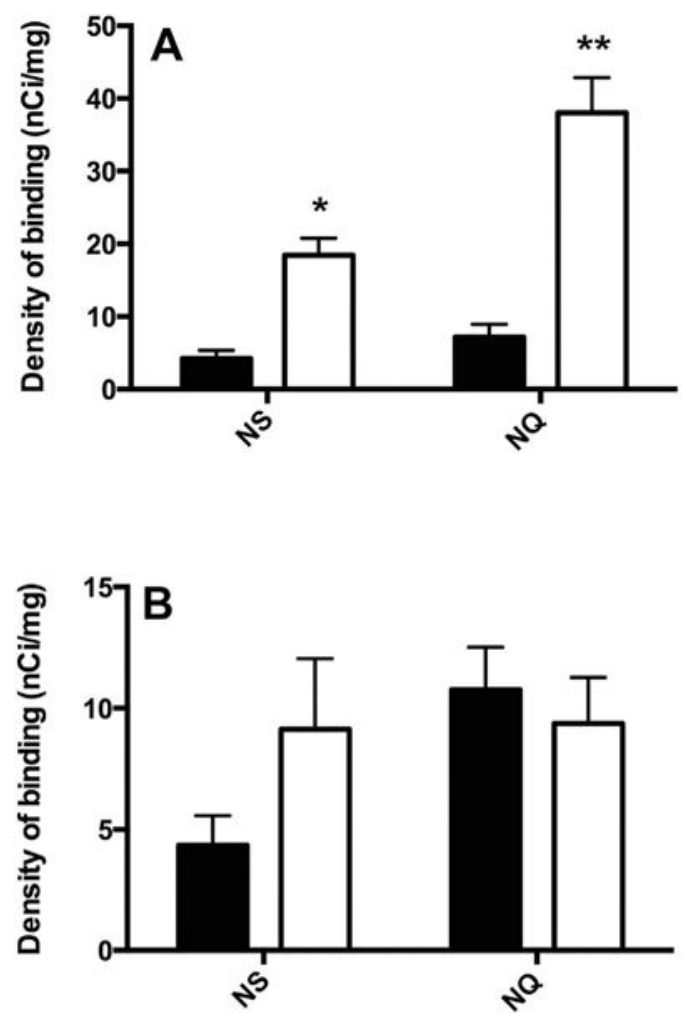

Fig. 5.

The density of binding $(\mathrm{nCi} / \mathrm{mg})$ is presented as a function of neonatal drug treatment ( $\mathrm{x}$ axis) and adolescent drug treatment (legend) $\alpha 4 \beta 2 \mathrm{nAChR}$ binding in the NAcc (A) and dorsal striatum (B). In the NAcc, NQ administered SN demonstrated significantly higher a $4 \beta 2$ nAChR binding than all other groups (indicated by **, p < 0.05). Group NS administered SN demonstrated significantly higher a $4 \beta 2 \mathrm{nAChR}$ binding than controls administered SS (indicated by $*, p<0.05$ ). In the dorsal striatum, there were no significant differences between groups. 